\title{
All Single-Mode-Fiber Supercontinuum Source Setup for Monitoring of Multiple Gases Applications
}

\author{
Javier A. Martin-Vela ${ }^{1}$, Eloisa Gallegos-Arellano ${ }^{2, *}$, Juan M. Sierra-Hernández ${ }^{1}$, \\ Julián M. Estudillo-Ayala ${ }^{1}{ }^{\circledR}$, Daniel Jauregui-Vázquez ${ }^{1}$, Maria S. Avila-Garcia ${ }^{3}$, \\ Humberto Ramírez-Gasca ${ }^{2}$ and Roberto Rojas-Laguna ${ }^{1}$ \\ 1 Departamento de Ingenieria Electronica, Division de Ingenierias, Universidad de Guanajuato, Carretera \\ Salamanca-Valle de Santiago km 3.5 + 1.8, Comunidad de Palo Blanco, Salamanca Gto. C.P. 36885, Mexico; \\ ja.martinvela@ugto.mx (J.A.M.-V.); jm.sierrahernandez@ugto.mx (J.M.S.-H.); julian@ugto.mx (J.M.E.-A.); \\ jaureguid@ugto.mx (D.J.-V.); rlaguna@ugto.mx (R.R.-L.) \\ 2 Departamento de Mecatronica Universidad Tecnologica de Salamanca, Av. Universidad \#200, \\ Col. Ciudad Bajio, Salamanca Gto. C.P. 36766, Mexico; hramirez@utsalamanca.edu.mx \\ 3 Departamento de Estudios Multidisciplinarios, Division de Ingenierias, Universidad de Guanajuato, \\ Av. Universidad s/n, Col. Yacatitas, Yuriria Gto. C.P. 38940, Mexico; susana.avila@ugto.mx \\ * Correspondence: egallegos@utsalamanca.edu.mx; Tel.: +52-464-647-3861
}

Received: 14 May 2020; Accepted: 4 June 2020; Published: 6 June 2020

\begin{abstract}
In this paper, a gas sensing system based on a conventional absorption technique using a single-mode-fiber supercontinuum source (SMF-SC) is presented. The SC source was implemented by channeling pulses from a microchip laser into a one kilometer long single-mode fiber (SMF), obtaining a flat high-spectrum with a bandwidth of up to $350 \mathrm{~nm}$ in the region from 1350 to $1700 \mathrm{~nm}$, and high stability in power and wavelength. The supercontinuum radiation was used for simultaneously sensing water vapor and acetylene gas in the regions from 1350 to $1420 \mathrm{~nm}$ and 1510 to $1540 \mathrm{~nm}$, respectively. The experimental results show that the absorption peaks of acetylene have a maximum depth of approximately $30 \mathrm{~dB}$ and contain about 60 strong lines in the $R$ and $P$ branches, demonstrating a high sensitivity of the sensing setup to acetylene. Finally, to verify the experimental results, the experimental spectra are compared to simulations obtained from the Hitran database. This shows that the implemented system can be used to develop sensors for applications in broadband absorption spectroscopy and as a low-cost absorption spectrophotometer of multiple gases.
\end{abstract}

Keywords: absorption spectroscopy; supercontinuum source; fiber optics; fiber optic measurements; broadband; gas sensing; real-time monitoring; multiple gases

\section{Introduction}

In recent years, various types of optical setups have been proposed for sensing and monitoring different gases, such as $\mathrm{H}_{2} \mathrm{O}, \mathrm{H}_{2} \mathrm{~S}, \mathrm{CO}_{2}, \mathrm{C}_{2} \mathrm{H}_{2}, \mathrm{CH}_{4}$, and $\mathrm{He}$, by means of absorbing radiation in the near infrared range [1-8]. Many of these setups are based on a spectroscopic absorption principle since atoms absorb light at specific wavelengths [9]. There are different techniques that are based on this principle and are used for gas monitoring and sensing such as: Tunable Diode-Laser Absorption Spectroscopy (TDLAS) [10-18], Tunable Laser Absorption Spectroscopy (TLAS) [19-21], Cavity Ring-Down Spectroscopy (CRDS) [19,22,23], Cavity Enhanced Absorption Spectroscopy (CEAS) [24], Fiber Laser Intracavity Absorption Spectroscopy (FLICAS) [25,26], gas cell with coreless fiber optic $[27,28]$, or measurement of the incident and transmitted intensity of light travelling through a medium $[29,30]$.

Some of these techniques use laser diodes, lasers, or tunable lasers for their high output power, narrow wavelength, and high resolution, however the poor stability of these parameters and the narrow 
measurable bandwidth limit the applicability of devices based on these techniques since they are tuned to detect and measure only certain absorption peaks of the molecule. Therefore, broad spectrum sources, such as those reported using Amplified Spontaneous Emission (ASE) sources [25,26,31-33], Super-luminescent Diodes (SLD) [29,30,34,35], Xenon arc lamps [36,37], and supercontinuum (SC) sources $[34,35,38-49]$, are alternative sources that can be used to detect and measure the concentration of a pure gas or mixtures of gases. SC sources are built using a fiber laser pump and fiber optic [46] and are particularly useful given their wide bandwidth and output power when compared to ASE and SLD sources [34]. In Reference [38], the authors designed a SC source by connecting in series a femtosecond fiber laser emitting at $1560 \mathrm{~nm}$, a non-linear fiber, a dispersive fiber, and a tunable spectral bandpass filter, and detected the absorption bands of $\mathrm{CO}_{2}, \mathrm{C}_{2} \mathrm{H}_{2}, \mathrm{C}_{2} \mathrm{H}_{6} \mathrm{O}$, and $\mathrm{H}_{2} \mathrm{O}$. Genty et al. [40] proposed an array of micro-structured fibers combining a SC source and a gas cell in a single micro-structured fiber. The SC source was obtained by launching nanosecond pulses from a compact, Q-switched Nd:YAG laser into a micro-structured fiber filled with acetylene.

A SC source was also obtained by launching 5 ps laser pulses, centered around $1060 \mathrm{~nm}$, into $10 \mathrm{~m}$ of conventional single-mode fiber (Corning SMF28, Charlotte, NC, USA). The pump laser was an Ytterbium fiber laser (Fianium, FemtoPower-1060, NKT Photonics Inc., Freehold, NJ, USA) featuring a variable repetition rate [44-47]. In Reference [44], a $\mathrm{CH}_{4}$ sensor used a SC source and a multi pass-cell technique, while in Reference [45] the collimated SC beam was passed through $2.8 \mathrm{~m}$ of air to measure absorption from the $\mathrm{H}_{2} \mathrm{O}$ molecule. In Reference [46], the study of lines between 1500 and $1550 \mathrm{~nm}$ of high-temperature $\mathrm{H}_{2} \mathrm{O}$ in a laminar flame was reported using a SC source, as well as the CEAS technique using pure $\mathrm{CO}_{2}$ lines to validate the ringdown measurement. In Reference [41], a SC source and the CEAS technique for detecting $\mathrm{O}_{2}$ and $\mathrm{C}_{2} \mathrm{H}_{2}$ was reported. The SC source was obtained by pumping $20 \mathrm{~m}$ of a highly nonlinear photonic crystal fiber (SC-5.0-1040, Crystal Fiber, NKT Photonics Inc., Morganville, NJ, USA) with $1.064 \mu \mathrm{m}$ light from a Q-switched laser producing $10 \mathrm{~ns}$ pulse at a repetition rate of $30 \mathrm{kHz}$. In Reference [34], the authors used a SC source and the CEAS technique for detection of $\mathrm{CO}_{2}$ and $\mathrm{CH}_{4}$. The SC source was obtained by injecting 700 ps pulses from an ultra-compact fiber laser (Keopsys Kult, Keopsys, Lannion, France) operating at $1.5 \mu \mathrm{m}$ into the anomalous dispersion regime of a standard single-mode fiber (Ocean UltraWave SLA, Furukawa, Tokio, Japan). In Reference [47], a SC emission was used to acquire high-resolution broadband absorption spectra of $\mathrm{H}_{2} \mathrm{O}, \mathrm{C}_{2} \mathrm{H}_{2}$, and $\mathrm{C}_{2} \mathrm{H}_{4}$. Brown et al. [42] reported an experimental setup for measuring indoor and outdoor path absorption of water vapor concentrations using Differential Absorption Spectroscopy (DAS) and Spectral Pattern Recognition Differential Absorption Lidar (SPR-DIAL) techniques and a SC source. The SC was implemented by coupling sub-nanosecond laser pulses from a passively Q-switched microchip laser (JDSU NP-10620-100, JDS Uniphase corporation, San Jose, CA, USA, wavelength at $1064 \mathrm{~nm}$, average power $70 \mathrm{~mW}$ ) into $18 \mathrm{~m}$ of photonic crystal fiber (Blaze Photonics SC-5.0-1040, Thorlabs Inc., Newton, NJ, USA). Recently, a supercontinuum source was used to measure the concentration of light hydrocarbon species that are found in fuel and energy applications, such as methane, acetylene, ethylene, and their mixtures [49].

In this work, a gas sensing system based on a conventional absorption technique and employing a single mode fiber supercontinuum source (SMF-SC) is presented. The SC source was implemented using pulses from a microchip laser and one kilometer of standard single-mode fiber (SMF), obtaining a flat high spectrum with a bandwidth of up to $350 \mathrm{~nm}$ in the region from 1350 to $1700 \mathrm{~nm}$. High sensibility for real time acetylene and water vapor gas detection is achieved using such SC source and a cm-long conventional cell. The results are compared with those obtained using an EDFA source, a super luminescent diode, and the Hitran database. 


\section{Experimental Setup and Principal Operation of the System}

\subsection{Experimental Setup}

In our experiment, a supercontinuum source (SCS) was used as a broadband source (see Figure 1a). Here, the SCS was implemented by pumping $1 \mathrm{~km}$ of a SMF on a spool with a microchip laser. The laser emits pulses with a duration of $\sim 700 \mathrm{ps}$, an energy of $6 \mu \mathrm{J}$, a repetition rate of $8.6 \mathrm{KHz}$, and a central wavelength of $1064 \mathrm{~nm}$. An optical microscope objective with a magnification of 16×, and a XYZ positioner stage were used to launch the pump power from the microchip into the spool. The output light of the spool was coupled to a gas cell with a path length of $18.5 \mathrm{~cm}$, reaching another microscope objective. Finally, the transmitted light was connected on an optical spectrum analyzer (OSA) with a resolution of $0.02 \mathrm{~nm}$ via a multimode fiber. With an input power of about $40 \mathrm{~mW}$ in the fiber spool, the spectrum of the pump pulse shifts to both shorter and longer wavelengths, as it is shown in Figure 2 . This broadband emission is due to nonlinear effects such as modulation instability, four waves mixing, and self and cross phase modulation. For this paper, we implemented the SC source proposed in Reference [50] and in References [51,52].

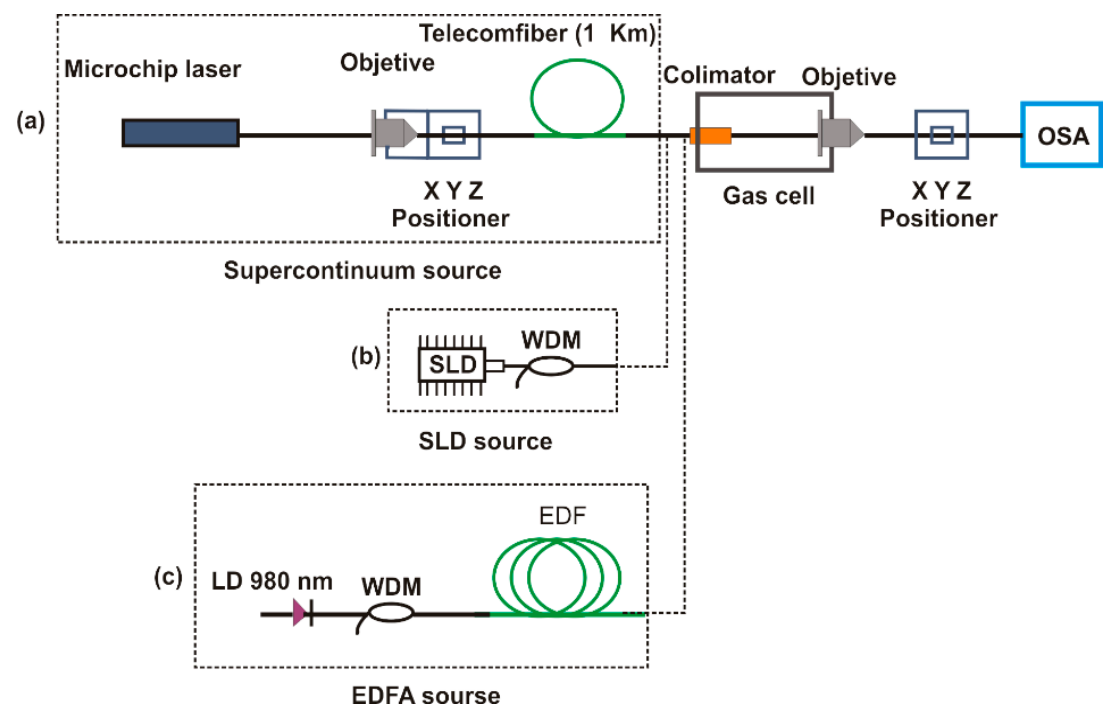

Figure 1. Experimental setup (a) Light from the supercontinuum (SC), (b) light from the Super-luminescent Diodes (SLD), (c) light from erbium-doped fiber amplified (EDFA). All are coupled to a fiber optic collimator.

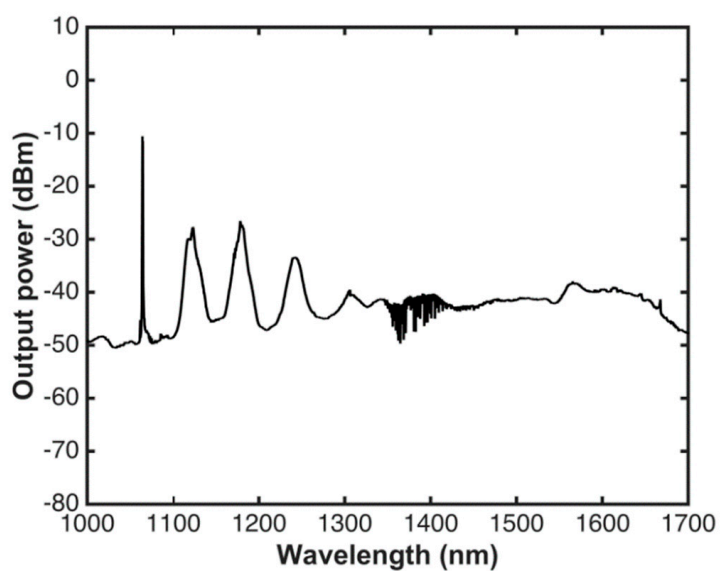

Figure 2. Spectral profile of the supercontinuum radiation. 
The supercontinuum source presented in this work was compared to two other broad-spectrum sources: a super luminescent diode (SLD: QSMD-1550-I, Qphotonics, Ann Arbor, MI, USA) that emitted from 1400 to $1600 \mathrm{~nm}$ (Figure 1b) and an erbium-doped fiber amplified (EDFA) source (Figure 1c).

The EDFA source was obtained by pumping $3.5 \mathrm{~m}$ of erbium-doped fiber (Thorlabs, model M12-980-125, Newton, NJ, USA) with a 976 nm laser diode (Thorlabs, model BL976-PAG500, Newton, NJ, USA), obtaining a broadband spectrum from 1500 to $1600 \mathrm{~nm}$.

Figure 2 shows the output spectrum of the SC source with a power of about $40 \mathrm{~mW}$ in the spectral region of interest, stretching from 1300 to $1700 \mathrm{~nm}$ for near-IR (Infrared) absorption spectroscopy of a large number of molecules, such as $\mathrm{H}_{2} \mathrm{O}, \mathrm{C}_{2} \mathrm{H}_{2}, \mathrm{CO}, \mathrm{CO}_{2}, \mathrm{~N}_{2} \mathrm{O}$, and $\mathrm{H}_{2} \mathrm{~S}$, among others. The absorption lines observed in the region stretching from 1340 to 1450 correspond to rovibrational overtone transitions of water vapor present in the system. Some studies show these bands of $\mathrm{H}_{2} \mathrm{O}$ as an example of the broadband capability of an SC-based sensor [45,47]. On the other hand, as it can be observed in Figure 2, the spectral response shape presents a high-intensity relative noise related to the pump emitting in the picosecond regime; as a result, the spectral broadening is generated mainly by a modulation instability (MI) phenomenon [53]. The MI is produced by breaking up of the pulse in many fundamental solitons, when they collide and re-combine in a chaotic manner. For this reason, the MI is a noisy process $[54,55]$.

A direct comparison between the SLD, EDFA, and SC spectra in the wavelength band from 1510 to $1540 \mathrm{~nm}$, where acetylene has strong absorption peaks, is shown in Figure 3. This figure illustrates the advantage of using the SC source for broadband spectroscopy with a power-bandwidth output wider than that of the SLD and EDFA; furthermore, the SC spectra is flat in this region. In Reference [34], it has been demonstrated that the wider the output power-bandwidth of the source, the higher the sensibility.

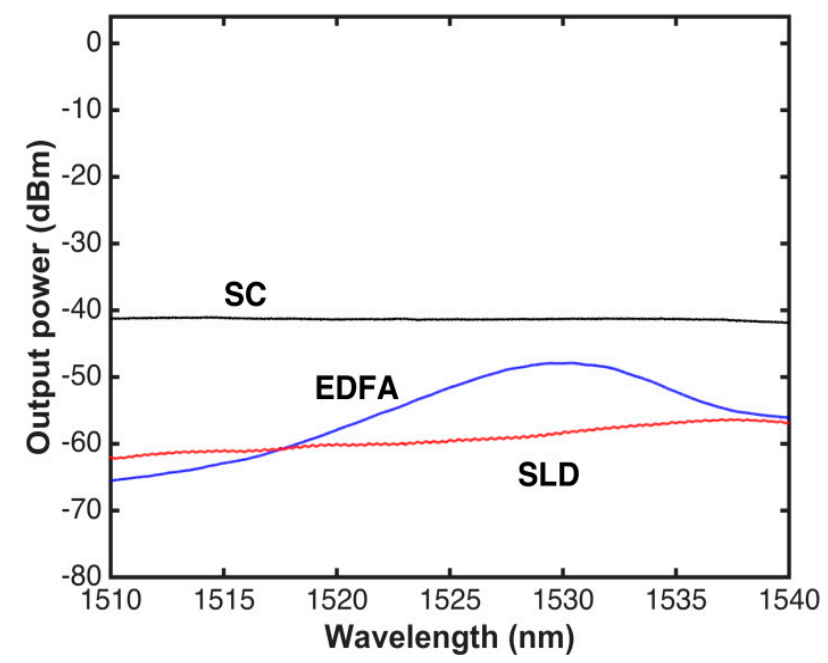

Figure 3. Comparison of supercontinuum (SC), super-luminescent (SLD), and fiber amplification doped with erbium (EDFA).

The system comprises a gas cell constructed from a stainless-steel tube of $21.5 \mathrm{~cm}$ in length and $2.54 \mathrm{~cm}$ in diameter. In addition, the cell has two ports to introduce and evacuate the gas, as shown in Figure 4. Instead of windows at its ends, like a conventional cell, this one has at one end an optical fiber collimator to transmit the light coming from the source through the cell, and at the other end, a target that receives the signal and transmits it to the OSA by means of a multimode fiber (see Figure 1). It is important to note that the system must be adjusted to obtain the highest power and sensitivity. 


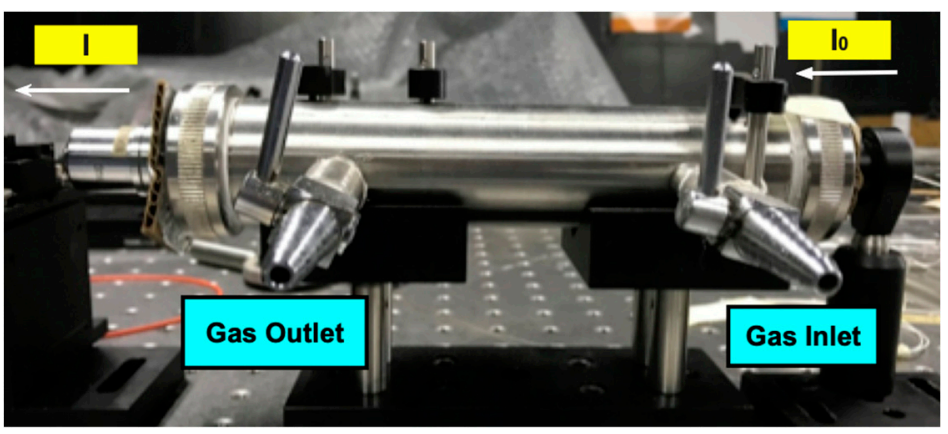

Figure 4. Gas cell.

\subsection{Operation of the System}

The system is based on the principle of absorption spectroscopy: the total transmission of light through a gas path length is described by the Beer-Lambert-Bouguer law given by $[47,56]$ :

$$
T(\lambda, N)=\frac{I(\lambda, N)}{I_{0}(\lambda)}=e^{-L N \sigma(\lambda)}
$$

where $I_{0}(\lambda)$ is the light incident intensity, $I(\lambda, N)$ is the light transmitted intensity of broadband source through a gas cell before and after introducing the target gas (acetylene) into the gas cell respectively, $L$ is the gas cell path length $(\mathrm{cm}), \sigma(\lambda)$ is the absorption cross-section $\left(\mathrm{cm}^{2} / \mathrm{molecule}\right)$, and $N$ is the number density $\left(\right.$ molecule $\left./ \mathrm{cm}^{3}\right)$, which can be calculated as [57]:

$$
N=q P /\left(k_{b} T\right)
$$

where $T$ and $P$ are the temperature and pression of the system respectively, $q$ is the mole fraction, and $k_{b}$ is the Boltzmann constant. In this study, the absorption cross-section is estimated by considering the given experimental conditions and the Hitran database [58-60].

The simulations of the absorption spectra were carried out using Equations (1) and (2). The gas cell path length is $18.5 \mathrm{~cm}$ and the number density (concentration) of the target gas (in our case acetylene) is varied. Figure 5 shows simulation results of the transmission of acetylene, with $P=1$ atm and $T=296 \mathrm{~K}$, where it can be seen that as the gas concentration increases, a widening in the absorption line occurs, and an increase in amplitude of the absorption line is also seen.

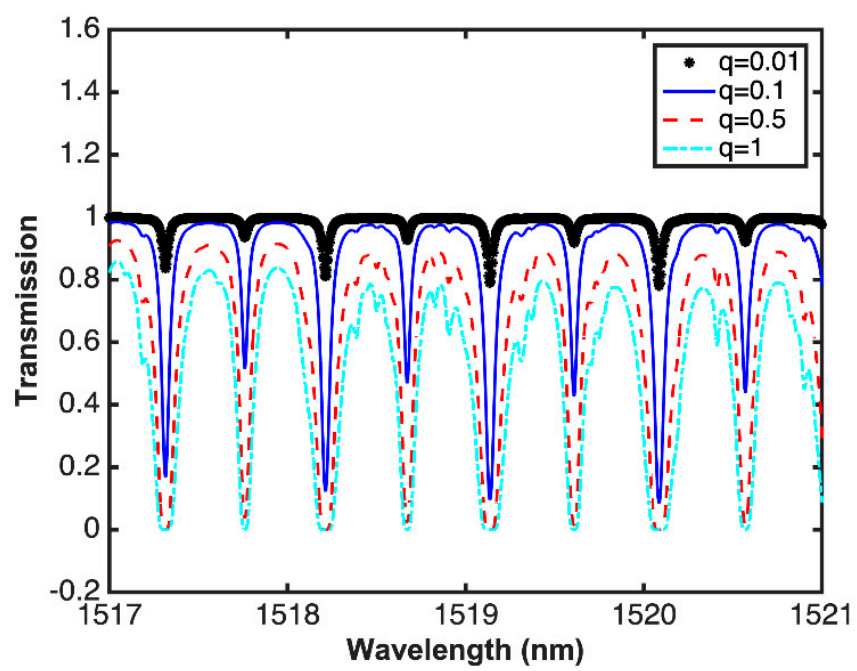

Figure 5. Simulations of the acetylene transmission power at different concentrations. 


\section{Results and Discussion}

Once each one of the sources was inserted, and the experimental set-up aligned, the cell was filled with $99.5 \%$ pure acetylene and measurements were made at atmospheric pressure and at room temperature. Figure 6 shows a comparison of the measurements where a supercontinuum source with a higher power-bandwidth output can provide a greater amplitude in the absorption line, as it can be seen in the R branch of the spectrum, and consequently can increase the sensitivity of the system, as demonstrated in Reference [34]. This is also shown in Figure 6b, where a magnified view of lines 29, 31, and 33, with limited absorption is shown. Furthermore, measurements with SC source show a deeper dip and better-defined absorption lines.

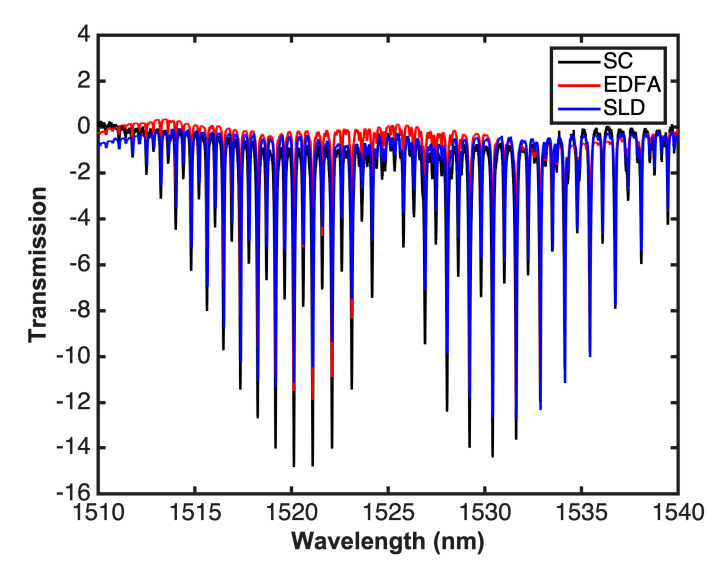

(a)

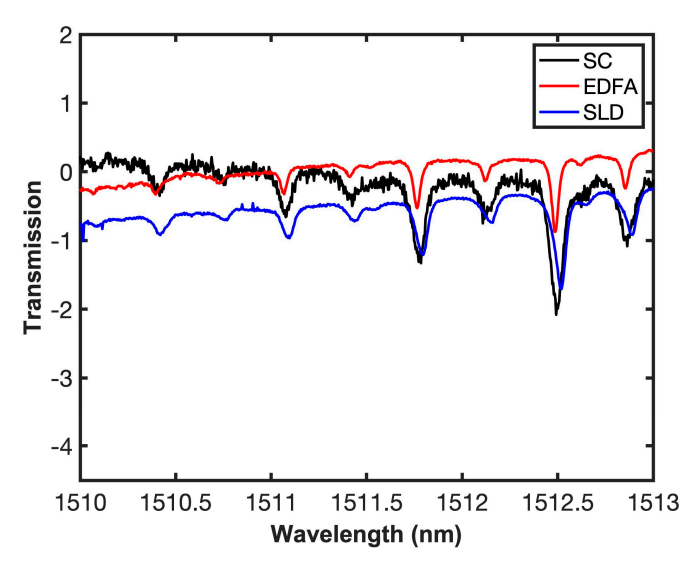

(b)

Figure 6. (a) Gas transmission with SC, SLD, EDFA, and (b) magnified view of 1510-1513 nm region.

Figure 7 shows a comparison of the measurements of Gas transmission with SC, SLD, EDFA, and the simulation using the parameters provided by the Hitran database, where it can be observed that the absorption lines of the simulated data are deeper, while the depth of the experimental data are limited by the sensitivity of the system.

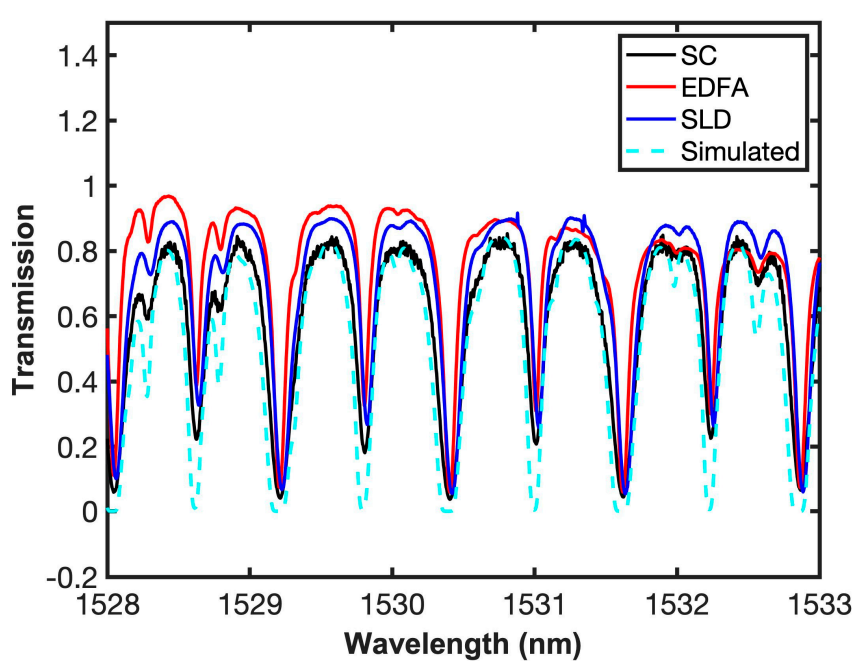

Figure 7. Measured and simulated gas transmission with SC, SLD, and EDFA.

After a subsequent alignment, a greater sensitivity was obtained. Figure 8 a shows that the absorption peaks have a maximum depth of approximately $30 \mathrm{~dB}$ and contain about 60 strong lines in the $R$ and $P$ branches of the 1510 to $1540 \mathrm{~nm}$ wavelength band. Compared to the measurements 
shown in Figure 6a, with this new alignment, a greater sensitivity can be obtained, and it is possible to have a wider detection range of ${ }^{12} \mathrm{C}_{2} \mathrm{H}_{2}$ acetylene ( $\mathrm{v} 1+\mathrm{v} 3$ rotational-vibrational combination band). Figure 8 b shows lines 29-33 of the $\mathrm{R}$ branch clearly, which have little intensity or depth and are not commonly detected or monitored in the reported investigations [24,27,39,40], and much less using a supercontinuum source $[1,39,47]$. When comparing Figures $6 \mathbf{b}$ and $8 \mathbf{b}$, it can be observed that the sensibility increases when introducing higher power into the system. However, as it can be observed in Figure 8b, the spectral response shape shows some noise due to the modulation instability phenomenon. As it was mentioned previously, the MI is a noisy process induced when using a pump laser in picosecond regime [54,55]. Although this noise can be reduced by changing both the laser pumping and the type of fiber optic, this will increase the cost of the experimental setup.

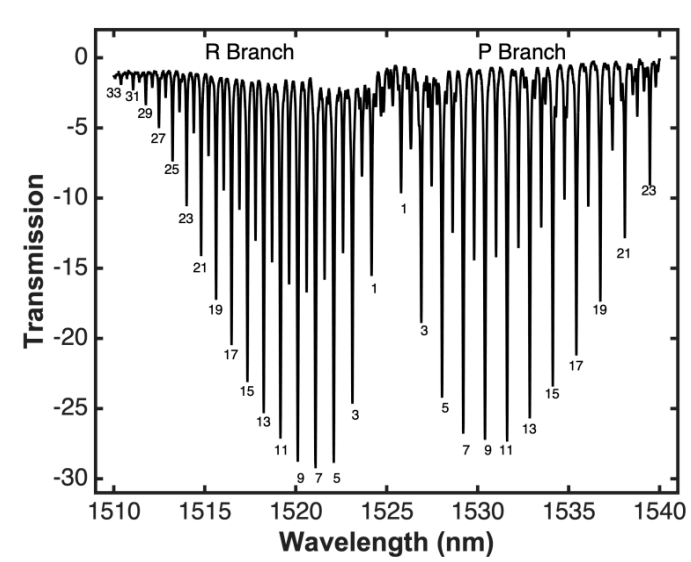

(a)

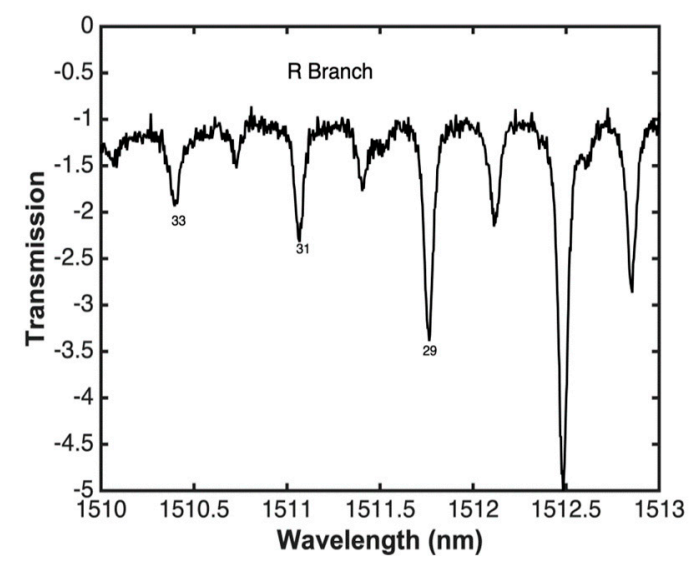

(b)

Figure 8. (a) Transmission of acetylene, (b) magnified view of lines 29, 31, and 33.

To check the stability and measurement of the system in time, the monitoring of the gas concentration was performed by opening one of the valves of the cell to escape some gas. Figure 9 shows the real-time monitoring of the gas using a SCS, in 15 min time intervals, where it can be observed that as time goes by, the widening in the absorption line as well as its amplitude decrease. According to the simulations performed, the system provides a change in the concentration of gas in the cell.

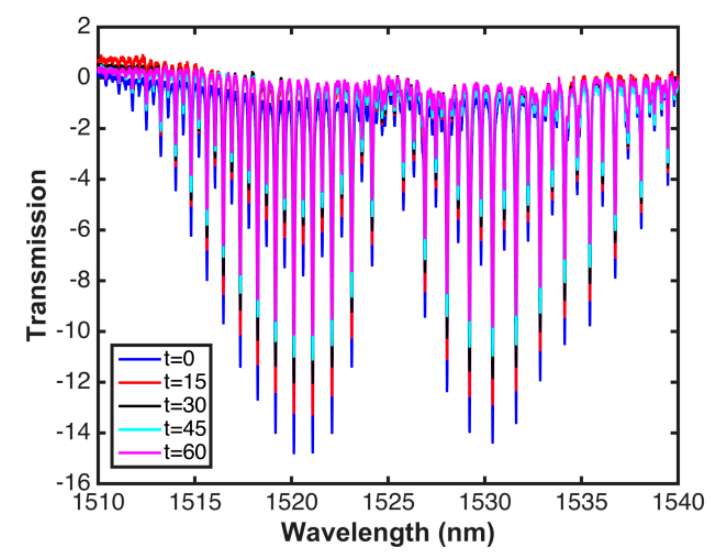

(a)

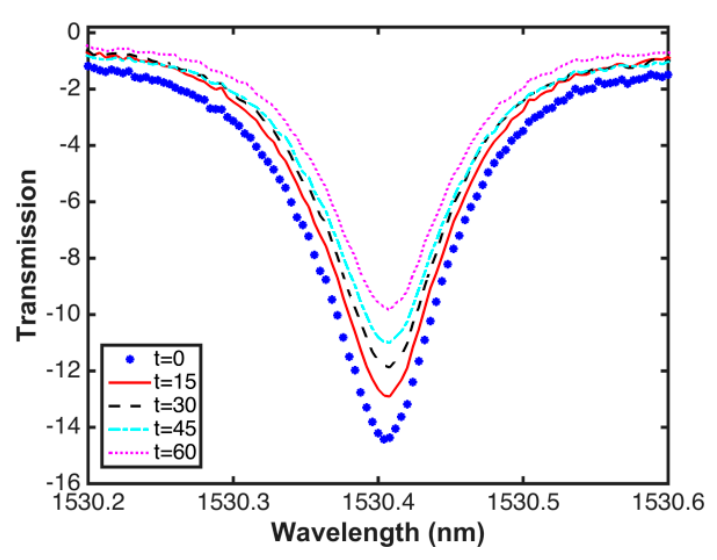

(b)

Figure 9. (a) Real-time gas monitoring with the OSA, (b) magnified view of 1530.2-1530.6 nm region.

Measurements were carried out by changing the concentration (molar fraction) of the gas inside the cell. Figure 10 shows a comparison between acetylene transmission in the experimental system 
(qm) using an OSA and the simulations (qs) using the parameters provided by the Hitran database, when $q=1, q=0.25$, and $q=0.1$. As it can be seen, as the concentration increases, there is a widening in the absorption line, and it can also be observed that the behavior is consistent with the simulation of the system when varying the concentration. For better illustration purposes, Figure 11a shows a single comparison when $q=1$ in the $P$ Branch. It can be observed that the high resolution of the proposed system provides a clear identification of spectral lines in the $P$ and $R$ branches of acetylene ${ }^{12} \mathrm{C}_{2} \mathrm{H}_{2}$. Furthermore, the system provides a wide wavelength coverage allowing to visualize complete spectral bands of one or more gases. Figure $11 \mathrm{~b}$ shows both experimental and simulation results in the region between 1354 and $1357 \mathrm{~nm}$, where the water vapor has an absorption band. However, as it can be observed in Figures 10 and 11, the spectral response shape shows some discrepancies between transmission in the experimental system and the simulations, due to the broadening effect [61-63].

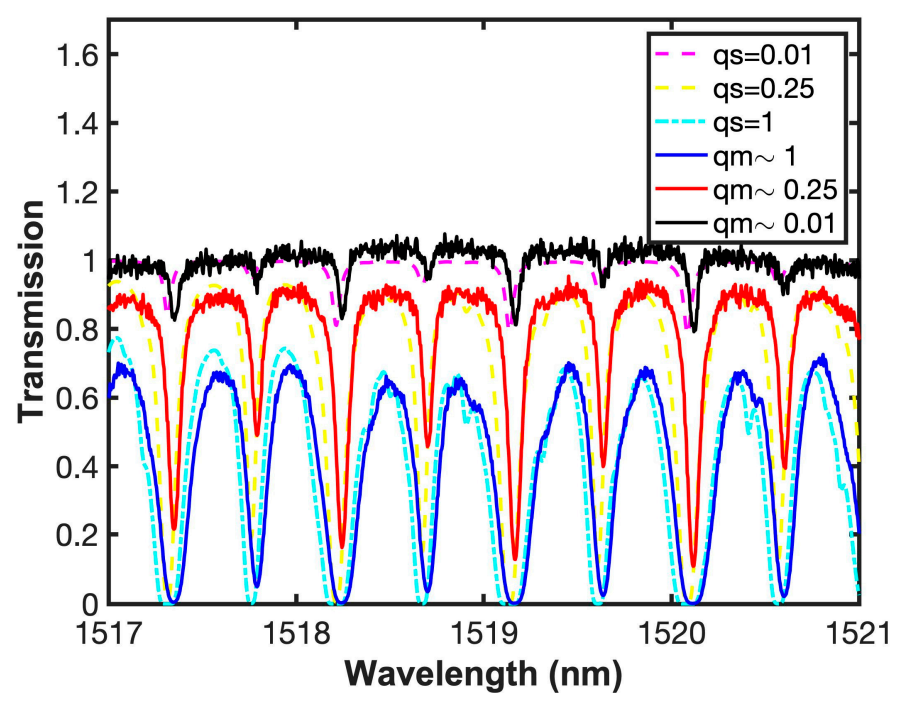

Figure 10. Measured (qm) and simulated (qs) gas transmission at different concentrations.

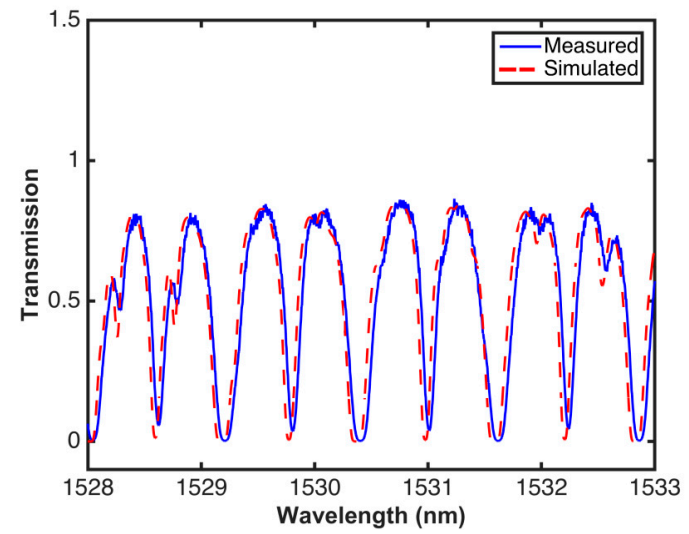

(a)

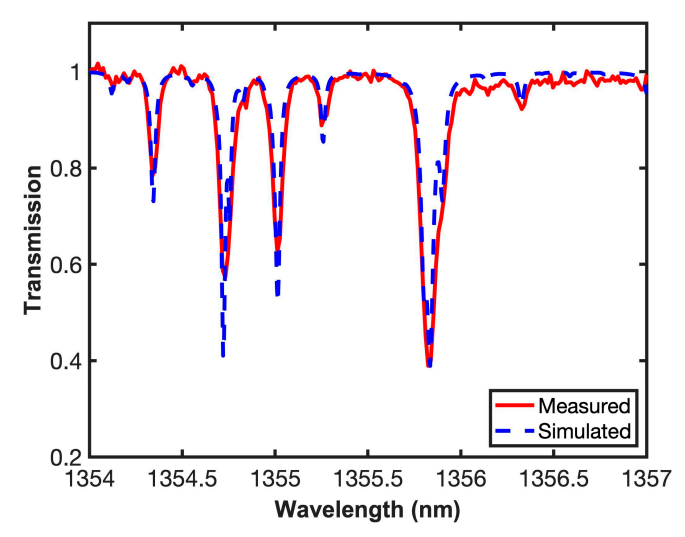

(b)

Figure 11. Simulated and simultaneously measured gas transmission of (a) acetylene and (b) water vapor.

The proposed system does not show insertion losses since the whole arrangement is made of single-mode fiber which also makes it cheaper to manufacture compared to those made with photonic crystal fiber, which cannot be spliced to conventional fibers. Another advantage of the system is that it provides a broad wavelength coverage that allows to simultaneously visualize complete spectral bands of one or more gases, and due to its high resolution, allows the clear identification of the spectral lines of the gases. Moreover, it has high power and wavelength stability. In this work, the ${ }^{12} \mathrm{C}_{2} \mathrm{H}_{2}$ acetylene 
bands in the $R$ and $P$ branches between 1510 and 1540 as well as the water vapor bands between 1354 and $1410 \mathrm{~nm}$ were visualized. The high sensitivity of the system with a path length of $18.5 \mathrm{~cm}$ using a manufactured cell was experimentally demonstrated, and it was shown that the system needs to be aligned to obtain the highest power and sensitivity. In this system, it was not necessary to lengthen the path length to increase sensitivity as it has been reported in other works. Finally, the experimental results were compared by running simulations with the data provided by the Hitran database.

\section{Conclusions}

A gas sensing system based on a conventional absorption technique by using an all single mode fiber supercontinuum source (SMF-SC) was used to simultaneously measure acetylene and water vapor. The supercontinuum source was implemented using pulses from a microchip laser and one kilometer of standard single-mode fiber (SMF), obtaining a flat, high spectrum with a bandwidth of up to $350 \mathrm{~nm}$ in the region from 1350 to $1700 \mathrm{~nm}$, and high stability in power and wavelength. The implemented system can be used for different applications of broadband absorption spectroscopic, such as chemical analysis and simultaneous real-time monitoring of multiple gases. It can also be used to develop sensors for multiple gases or a low-cost absorption spectrophotometer capable of detecting the absorption peaks of multiple gases.

Author Contributions: Data Curation, J.A.M.-V.; Formal Analysis, D.J.-V. and J.A.M.-V.; Investigation, H.R.-G.; Methodology, E.G.-A. and J.M.S.-H.; Software, M.S.A.-G.; Supervision, R.R.-L.; Validation, J.M.E.-A.; Visualization, M.S.A.-G.; Writing-Original Draft Preparation, J.M.S.-H.; Writing-Review \& Editing, E.G.-A. All authors have read and agreed to the published version of the manuscript.

Funding: This work was partially supported by the Universidad de Guanajuato, project CIIC 285/2020 and 183893 CONACYT project. J. A. Martin-Vela was supported by CONACyT grant No. 104400-439673.

Acknowledgments: We would like to thank Daniel Alejandro Ramos Gonzalez for the help with the Hitran data analysis.

Conflicts of Interest: The authors declare no conflict of interest.

\section{References}

1. Kelkar, P.V.; Coppinger, F.; Bhushan, A.S.; Jalali, B. Time-domain optical sensing. Electron. Lett. 1999, 35, 1661-1662. [CrossRef]

2. Weldon, V.J.; O'gorman, J.; Phelan, P.; Hegarty, J. H2S and CO2 gas sensing using DFB laser diodes emitting. Sens. Actuator B Chem. 1995, 29, 101-107. [CrossRef]

3. Zhang, Y.; Zhang, M.; Jing, W.; Demokan, M.S.; Culshaw, B.; Stewart, G. Investigation of erbium-doped fiber laser intra-cavity absorption sensor for gas detection. Opt. Commun. 2004, 234, 435-441. [CrossRef]

4. Marshall, J.; Stewart, G.; Whitenett, G. Design of a tunable L-band multi-wavelength laser system for application to gas spectroscopy. Meas. Sci. Technol. 2006, 17, 1023-1031. [CrossRef]

5. Kiefer, J. Design and characterization of a Raman-scattering-based sensor system for temporally resolved gas analysis and its application in a gas turbine power plant. Meas. Sci. Technol. 2008, 19, 85408. [CrossRef]

6. Niermann, B.; Budunoglu, I.L.; Gurel, K.; Winter, J. Application of a mode-locked fiber laser for highly time resolved broadband absorption spectroscopy and laser-assisted breakdown on micro-plasmas. J. Phys. $D$ Appl. Phys. 2012, 45, 245202. [CrossRef]

7. Thompson, A.; Northern, H.; Williams, B.; Hamilton, M.; Ewart, P. Simultaneous detection of CO2 and CO in engine exhaust using multi-mode absorption spectroscopy, MUMAS. Sens. Actuators B Chem. 2014, 198, 309-315. [CrossRef]

8. Vargas-Rodriguez, E.; Guzman-Chavez, A.D.; Raja-Ibrahim, R.K.; Cardoso-Lozano, L.E. Gas Sensor Design Based on a Line Locked Tunable Fiber Laser and the Dual Path Correlation Spectroscopy Method. Appl. Sci. 2017, 7, 958. [CrossRef]

9. Struve, W.S. Fundamental of Molecular Spectroscopy; John Wiley \& Sons, Inc.: Chichester, UK, 1989; pp. 1-104.

10. Werle, P.; Mücke, R.; Slemr, F. The limits of signal averaging in atmospheric trace-gas monitoring by tunable diode-laser absorption spectroscopy (TDLAS). Appl. Phys. B Photophys. Laser Chem. 1993, 57, 131-139. [CrossRef] 
11. Werle, P.; Slemr, F.; Maurer, K.; Kormann, R.; Mücke, R.; Jänker, B. Near- and mid-infrared laser-optical sensors for gas analysis. Opt. Lasers Eng. 2002, 37, 101-114. [CrossRef]

12. Bowling, D.R.; Sargent, S.D.; Tanner, B.D.; Ehleringer, J.R. Tunable diode laser absorption spectroscopy for stable isotope studies of ecosystem-atmosphere CO2exchange. Agric. For. Meteorol. 2003, 118, 1-19. [CrossRef]

13. Ebert, V.; Fleming, J.W. Optical Oxygen Sensors using Tunable Diode Laser Spectroscopy: Application to Harsh Reactive Processes. In Proceedings of the Sensors IEEE, Atlanta, GA, USA, 28-31 October 2007; pp. 616-619.

14. Liu, X.; Zhou, X.; Jeffries, J.B.; Hanson, R.K. Experimental study of H2O spectroscopic parameters in the near-IR (6940-7440 cm - 1) for gas sensing applications at elevated temperature. J. Quant. Spectrosc. Radial. Transf. 2007, 103, 565-577. [CrossRef]

15. Verma, R.; Kamble, S.S.; Radhakrishnan, J.K.; Krishnapur, P.P.; Padki, V.C. Tunable Diode Laser Absorption Spectroscopy based Oxygen Sensor. In Proceedings of the 6th International Conference on Sensing Technology (ICST), Kolkata, India, 18-21 December 2012; pp. 130-135.

16. Ma, L.H.; Lau, L.Y.; Ren, W. Non-uniform temperature and species concentration measurements in a laminar flame using multi-band infrared absorption spectroscopy. Appl. Phys. B Lasers Opt. 2017, 123, 1-9. [CrossRef]

17. Ögren, Y.; Sepman, A.; Qu, Z.; Schmidt, F.M.; Wiinikka, H. Comparison of Measurement Techniques for Temperature and Soot Concentration in Premixed, Small-Scale Burner Flames. Energy Fuels 2017, 31, 11328-11336. [CrossRef]

18. Sepman, A.; Ögren, Y.; Qu, Z.; Wiinikka, H.; Schmidt, F.M. Tunable diode laser absorption spectroscopy diagnostics of potassium, carbon monoxide, and soot in oxygen-enriched biomass combustion close to stoichiometry. Energy Fuels 2019, 33, 11795-11803. [CrossRef]

19. Cousin, J.; Masselin, P.; Chen, W.; Boucher, D.; Kassi, S.; Romanini, D.; Szriftgiser, P. Application of a continuous-wave tunable erbium-doped fiber laser to molecular spectroscopy in the near infrared. Appl. Phys. B Lasers Opt. 2006, 83, 261-266. [CrossRef]

20. Ryu, H.Y.; Lee, W.K.; Moon, H.S.; Suh, H.S. Tunable erbium-doped fiber ring laser for applications of infrared absorption spectroscopy. Opt. Commun. 2007, 275, 379-384. [CrossRef]

21. Gallegos-Arellano, E.; Vargas-Rodriguez, E.; Guzman-Chavez, A.D.; Cano-Contreras, M.; Cruz, J.L.; Raja-Ibrahim, R.K. Finely tunable laser based on a bulk silicon wafer for gas sensing applications. Laser Phys. Lett. 2016, 13, 65102. [CrossRef]

22. O'Keefe, A. Integrated cavity output analysis of ultra-weak absorption. Chem. Phys. Lett. 1998, 293, 331-336. [CrossRef]

23. O'Keefe, A.; Deacon, D.A.G. Cavity ring-down optical spectrometer for absorption measurements using pulsed laser sources. Rev. Sci. Instrum. 1988, 59, 2544-2551. [CrossRef]

24. Bernhardt, B.; Ozawa, A.; Jacquet, P.; Jacquey, M.; Kobayashi, Y.; Udem, T.; Holzwarth, R.; Guelachvili, G.; Pique, N. Cavity-enhanced dual-comb spectroscopy. Nat. Photonics. 2010, 4, 55-57. [CrossRef]

25. Fomin, A.; Zavlev, T.; Rahinov, I.; Cheskis, S. A fiber laser intracavity absorption spectroscopy (FLICAS) sensor for simultaneous measurement of $\mathrm{CO}$ and $\mathrm{CO} 2$ concentrations and temperature. Sens. Actuators $B$ Chem. 2015, 210, 431-438. [CrossRef]

26. Löhden, B.; Kuznetsova, S.; Sengstock, K.; Baev, V.M.; Goldman, A.; Cheskis, S.; Pálsdóttir, B. Fiber laser intracavity absorption spectroscopy for in situ multicomponent gas analysis in the atmosphere and combustion environments. App. Phys. B Laser Opt. 2011, 102, 331-344. [CrossRef]

27. Ritari, T.; Tuominen, J.; Ludvigsen, H. Gas sensing using air-guiding photonic bandgap fibers. Opt. Express 2004, 12, 4080-4087. [CrossRef]

28. Frazão, O.; Silva, R.M.; Ferreira, M.S.; Santos, J.L.; Ribeiro, A.B.L. Suspended-core Fibers for Sensing Applications. Photonic Sens. 2012, 2, 118-126. [CrossRef]

29. Divya, K.; Sulochana, K.; Vasa, N.J.M. Superluminescentet Diode-Based Multiple-Gas Sensor for NH3 and H2O Vapor Monitoring. IEEE J. Top. Quantum Electron. 2012, 18, 1540-1546. [CrossRef]

30. Sulochana, K.; Akash, K.; Kumaravel, M.; Vasa, N.J. Development of super luminescent diode based sensing technique for multiple-gas monitoring. Int. J. Adv. Eng. Sci. Appl. Math. 2014, 6, 117-124. [CrossRef]

31. Jin, W.; Ho, H.L.; Cao, Y.C.; Ju, J.; Qi, L.F. Gas detection with micro- and nano-engineered optical fibers. Opt. Fiber Technol. 2013, 19, 741-759. [CrossRef] 
32. Yan, G.; Zhang, A.P.; Ma, G.; Wang, B.; Kim, B.; Im, J. Fiber-Optic Acetylene Gas Sensor Based on Microstructured Optical Fiber Bragg Gratings. IEEE Photonics Technol. Lett. 2011, 23, 1588-1590. [CrossRef]

33. Waechter, H.; Litman, J.; Cheung, A.H.; Barnes, J.A.; Loock, H. Chemical Sensing Using Fiber Cavity Ring-Down Spectroscopy. Sensors 2010, 10, 1716-1742. [CrossRef] [PubMed]

34. Aalto, A.; Genty, G.; Laurila, T.; Toivonen, J. Incoherent broadband cavity enhanced absorption spectroscopy using supercontinuum and superluminescent diode sources. Opt. Express 2015, 23, 25225-25234. [CrossRef] [PubMed]

35. Denzer, W.; Hancock, G.; Islam, M.; Langley, C.E.; Peverall, R.; Ritchie, G.A.D.; Taylor, D. Trace species detection in the near infrared using Fourier transform broadband cavity enhanced absorption spectroscopy: Initial studies on potential breath analytes. Analyst 2011, 136, 801-806. [CrossRef] [PubMed]

36. Orphal, J.; Ruth, A.A. High-resolutions Fourier-transform cavity-enhanced absorption spectroscopy in the near-infrared using an incoherent broad-band light source. Opt. Express 2008, 16, 19232-19243. [CrossRef]

37. Fiedler, S.E.; Hese, A.; Ruth, A.A. Incoherent broad-band cavity-enhanced absorption spectroscopy. Chem. Phys. Lett. 2003, 371, 284-294. [CrossRef]

38. Sanders, S.T. Wavelength-agile fiber laser using group-velocity dispersion of pulsed super-continua and application to broadband absorption spectroscopy. App. Phys. B Laser Opt. 2002, 802, 799-802. [CrossRef]

39. Walewski, J.W.; Sanders, S.T. High-resolution wavelength-agile laser source based on pulsed super-continua. Appl. Phys. B Lasers Opt. 2004, 79, 415-418. [CrossRef]

40. Ritari, T.; Genty, G.; Ludvigsen, H. Supercontinuum and gas cell in a single microstructured fiber. Opt. Lett. 2005, 30, 3380-3382. [CrossRef]

41. Johnston, P.S.; Lehmann, K.K. Cavity enhanced absorption spectroscopy using a broadband prism cavity and a supercontinuum source. Opt. Express 2008, 16, 15013-15023. [CrossRef]

42. Brown, D.M.; Shi, K.; Liu, Z.; Philbrick, C.R. Long-path supercontinuum absorption spectroscopy for measurement of atmospheric constituents. Opt. Express 2008, 16, 8457-8471. [CrossRef]

43. Langridge, J.M.; Laurila, T.; Watt, R.S.; Jones, R.L.; Kaminski, C.F.; Hult, J. Cavity enhanced absorption spectroscopy of multiple trace gas species using a supercontinuum radiation source. Opt. Express 2008, 16, 10178-10188. [CrossRef]

44. Hult, J.; Watt, R.S.; Kaminski, C.F. High bandwidth absorption spectroscopy with a dispersed supercontinuum source. Opt. Express 2007, 15, 11385-11395. [CrossRef]

45. Kaminski, C.F.; Watt, R.S.; Elder, A.D.; Frank, J.H.; Hult, J. Supercontinuum radiation for applications in chemical sensing and microscopy. Appl. Phys. B Lasers Opt. 2008, 92, 367-378. [CrossRef]

46. Watt, R.S.; Laurila, T.; Kaminski, C.F.; Hult, J. Cavity Enhanced Spectroscopy of High-Temperature $\mathrm{H}_{2} \mathrm{O}$ in the Near-Infrared Using a Supercontinuum Light Source. Appl. Spectrosc. 2009, 63, 1389-1395. [CrossRef] [PubMed]

47. Watt, R.S.; Kaminski, C.F.; Hult, J. Generation of supercontinuum radiation in conventional single-mode fibre and its application to broadband absorption spectroscopy. Appl. Phys. B Lasers Opt. 2008, 90, 47-53. [CrossRef]

48. Blume, N.G.; Ebert, V.; Dreizler, A.; Wagner, S. Broadband fitting approach for the application of supercontinuum broadband laser absorption spectroscopy to combustion environments. Meas. Sci. Technol. 2016, 27, 015501. [CrossRef]

49. Halloran, M.; Traina, N.; Choi, J.; Lee, T.; Yoo, J. Simultaneous Measurements of Light Hydrocarbons Using Supercontinuum Laser Absorption Spectroscopy. Energy Fuels 2020, 34, 3671-3678. [CrossRef]

50. Hernandez-Garcia, J.C.; Estudillo-Ayala, J.M.; Pottiez, O.; Rojas-Laguna, R.; Mata-Chavez, R.I. Generation of a spectrum with high flatness and high bandwidth in a short length of telecom fiber using microchip laser. Opt. Commun. 2013, 292, 126-130. [CrossRef]

51. Jauregui-Vazquez, D.; Lopez-Dieguez, Y.; Sierra-Hernandez, J.M.; Perez-Maciel, M.; Avila-Garcia, M.S.; Vargas-Rodriguez, E.; Rojas-Laguna, R.; Estudillo-Ayala, J.M. Modified all-fiber fabry-perot interferometer and its refractive index, load, and temperature analyses. IEEE Photonics J. 2015, 7, 1-9. [CrossRef]

52. Jauregui-Vazquez, D.; Estudillo-Ayala, J.M.; Rojas-Laguna, R.; Vargas-Rodriguez, E.; Sierra-Hernandez, J.M.; Gallegos-Arellano, E.; Claudio-Gonzalez, D. Lateral force sensing arrangement based on an all fiber Fabry-Perot interferometer. Optik 2015, 126, 5767-5770. [CrossRef] 
53. Hernandez-Garcia, J.C.; Estudillo-Ayala, J.M.; Mata-Chavez, R.I.; Pottiez, O.; Rojas-Laguna, R.; Alvarado-Mendez, E. Experimental study on a broad and flat supercontinuum spectrum generated through a system of two PCFs. Laser Phys. 2013, 10, 075101. [CrossRef]

54. Adamu, A.I.; Selim-Habid, M.; Smith, C.R.; Antonio-Lopez, J.E.; Jepsen, P.U.; Amezcua-Correa, R.; Bang, O.; Markos, C. Noise and spectral stability of deep-UV gas-filled fiber-based supercontinuum sources driven by ultrafast mid-IR pulses. Sci. Rep. 2020, 10, 4912. [CrossRef] [PubMed]

55. Egelsholm, R.D.; Bang, O. Supercontinuum noise reduction by fiber undertapering. Opt. Express 2019, 27, 10320-10331. [CrossRef] [PubMed]

56. Mishchenko, M.I. Directional radiometry and radiative transfer: The convoluted path from centuries-old phenomenology to physical optics. J. Quant. Spectrosc. Radiat. Transf. 2014, 146, 4-33. [CrossRef]

57. Emmert, J.; Blume, N.G.; Dreizler, A.; Wagner, S. Data analysis and uncertainty estimation in supercontinuum laser absorption spectroscopy. Sci. Rep. 2018, 8, 10312. [CrossRef]

58. Hill, C.; Gordon, I.E.; Kochanov, R.V.; Barrett, L.; Wilzewski, J.S.; Rothman, L.S. HITRANonline: An online interface and the flexible representation of spectroscopic data in the HITRAN database. J. Quant. Spectrosc. Radiat. Transf. 2016, 177, 4-14. [CrossRef]

59. Kochanov, R.V.; Gordon, I.E.; Rothman, L.S.; Wcisło, P.; Hill, C.; Wilzewski, J.S. HITRAN Application Programming Interface (HAPI): A comprehensive approach to working with spectroscopic data. J. Quant. Spectrosc. Radiat. Transf. 2016, 177, 15-30. [CrossRef]

60. Gordon, I.E.; Rothman, L.S.; Hill, C.; Kochanov, R.V.; Tan, Y.; Bernath, P.F.; Birk, M.; Boudon, V.; Campargue, A.; Chance, K.V.; et al. The HITRAN2016 molecular spectroscopic database. J. Quant. Spectrosc. Radiat. Transf. 2017, 203, 3-69. [CrossRef]

61. Galatry, L. Simultaneous effect of doppler and foreign gas broadening on spectral lines. Phys. Rev. 1961, 122, 1218-1223. [CrossRef]

62. Robert, D.; Bonamy, J. Short range force effects in semiclassical molecular line broadening calculations. Physique 1979, 40, 923-943. [CrossRef]

63. Rautian, S.G.; Sobel'man, J.I. The effect of collisions on the Doppler broadening of spectral lines. Sov. Phys. Usp 1967, 9, 701-716. [CrossRef]

(C) 2020 by the authors. Licensee MDPI, Basel, Switzerland. This article is an open access article distributed under the terms and conditions of the Creative Commons Attribution (CC BY) license (http://creativecommons.org/licenses/by/4.0/). 